\title{
Prevalence of Trypanosomosis of small ruminants in Guangua district of Awi Zone, northwestern Ethiopia
}

\author{
Nigatu Kebede ${ }^{1}$, Teshome Fetene ${ }^{2}$, Abebe Animut ${ }^{1}$ \\ ${ }^{1}$ Aklilu Lemma institute of Pathobiology, Addis Ababa University, Addis Ababa, Ethiopia \\ ${ }^{2}$ Adamitulu PPSC, Research and Development Department
}

J Infect Developing Countries 2009; 3(3):245-246.

Received 9 October 2008 - Accepted 5 February 2009

Copyright $(92009$ Kebede. This is an open-access article distributed under the Creative Commons Attribution License, which permits unrestricted use, distribution, and reproduction in any medium, provided the original work is properly cited.

\section{Small ruminant Trypanosomosis}

Sheep and goats play an important role in improving the economy of small holder farmers in Ethiopia. Tsetse-transmitted animal trypanosomosis is one of the most significant and costly diseases in the country, hindering the efforts being made for food self-sufficiency. In Ethiopia, about $200,000 \mathrm{~km}^{2}$ of the land is infested with tsetse flies [1] and the main pathogenic trypanosomes in animals are Trypanosoma congolense, T. vivax, and $T$. brucei. Although there have been several reports on livestock trypanosomosis, there is little data on the prevalence of trypanosomosis in sheep and goats in northwestern Ethiopia.

To provide this data, we collected blood into ethylenediaminetetraacetic acid (EDTA) from 600 adult sheep and 1,810 goats in five peasant associations (PAs) in the Guangua district of northwestern Ethiopia.

The packed cell volume (PCV) was measured and the buffy coat and uppermost layer of red blood cells were examined with phase contrast at $\mathrm{x} 400$ for the presence of motile trypanosomes [2]. Thick and thin blood smears were stained with Giemsa at 1:10 dilution for 30 minutes and examined under oil immersion for trypanosomes [3].

Standard tsetse fly traps (66 NGU and 20 Monoconical) [4] were deployed in the study PAs during the late rainy season and early dry season. All the traps were baited uniformly with octenol (1-oct-3nel) and acetone and left for 72 hours before collection.

Overall, trypanosomes were found in 5.6\% $(102 / 1810)$ of the samples, with more sheep being infected $(8.7 \%)$ than goats $(4.1 \%)(\mathrm{P}>0.01)$. The highest prevalence in a PA was recorded in sheep $(11.7 \%)$ but prevalences in each species did not vary significantly between PAs.

The trypanosomes identified in the blood smears were T. vivax, T. congolense, and T. brucei. All these organisms were found in sheep in each PA, but only T. vivax and T. congolense were found in goats in each PA. Trypanosoma brucei had the lowest overall prevalence, infecting only one goat $(0.1 \%)$ and eight sheep $(1.3 \%)$ in the five PAs. Trypanosoma vivax was the most common species found in sheep $(2.7 \%$; $1.8-4.2 \%)$ and goats (1.6\%; 1.3-1.7\%). Trypanosoma congolense was more common in goats $(1.5 \%$; 1.2 $2.2 \%)$ than sheep $(2.3 ; 1.3-3.3 \%)$. Mixed infections with $T$. vivax and $T$. congolense were common in both sheep and goats.

Animals with trypanosomes had significantly $(\mathrm{P}<$ 0.001) lower PCVs than uninfected animals (sheep $19.1 \%$ vs. $26 \%$ : goats $20.3 \%$ vs. $25.4 \%$ ).

Significantly more trypanosomes were trapped in the late rainy season $(9.5 \%$; $94 / 986)$ than in the early dry season $(1.0 \% ; 8 / 824)(\mathrm{P}<0.001)$. The trypanosome vectors identified in the traps were Glossina morsitans submorsitans, Glossina tachinoides and other biting flies of the Tabanidae (Tabanus and Chrysops) and Stomoxyinae (Stomoxys calcitrans) families.

Our findings on trypanosomes in northwestern Ethiopia are similar to those previously reported from the southwest of the country [5]. We found more sheep were infected than goats, which is consistent with findings in other studies $[6,7,8,9]$. The species we identified, T. congolense, T. vivax, and T. brucei, are the most notable causes of trypanosomosis of 
livestock in Sub-Saharan Africa. Further studies are indicated to determine whether the infected small ruminants we found are acting as reservoirs of infections for cattle in the area. Because cattle have lower trypanotolerance, infections in these animals result in greater economic losses.

We found that the prevalence of trypanosomosis was significantly higher in the wet season as compared to the dry season. This is likely because the tsetse fly vectors we found are more prevalent in the wet season $[10,11]$, leading to increased transmission of disease.

Although the microscopic technique used in our study has limited sensitivity, it provided important additional information on the prevalence of trypanosomosis in small ruminants in Ethiopia and showed the importance of the disease in the Guangua district. Further data can be provided with more sensitive techniques such as ELISA and PCR.

\section{Acknowledgement}

The authors would like to acknowledge staff members of Guangua district animal health personnel for their technical assistance. Financial support was obtained from Ethiopian Institute of Agricultural Research.

\section{References}

1. Keno M (2005) Situation of tsetse and trypanosomosis in Ethiopia. The International Scientific Council for Trypanosomiasis Research and Control (ISCTRC), in its 28th meeting, from 26th to 30th September,2005, in Addis Ababa, Ethiopia.

2. Paris J, Murray M, McOdimba F (1982) A comparative evaluation of the parasitological techniques currently available for the diagnosis of African trypanosomosis in cattle. Acta Trop 39: 307-316.
3. Murray MJCM, Trail JCM, Turner DA, Wissocq Y (1983) Livestock productivity and trypanotolerance, Network Trainning Manual, ILCA, pp, 4-10.

4. Drees MB, Jackman AJ (1998) A field guide to common Texas insects. Gulf publishing company, $1^{\text {st }}$ edition. Texas, USA pp.312-316.

5. Dinka H, Abebe G (2005) Small ruminants trypanosomosis in the southwest of Ethiopia. Small Rumin Res 57: 239-243.

6. Osaer S, Goossens B, Kora S, Gaye M, Darboe L (1999) Health and productivity of traditionally managed Djallonke sheep and West African dwarf goats under high and moderate trypanosomosis risk. Vet Parasitol 82: 109-119.

7. Masiga DK, Okech G, Irungu P, Ouma J, Wekesa S, Ouma B, Guya SO, Ndung'u JM (2002) Growth and mortality in sheep and goats under high tsetse challenge in Kenya. Trop Anim Hlth Prod 34: 489-501.

8. Fison TW (1987) Report of investigations carried out by the Veterinary Investigation Centre, Naliendele, Near Mtwara, Southern Tanzania 1984-1986. ODA, UK.

9. Ng'ayo MO, Njiru ZK, Kenya EU, Muluvi GM, Osir EO, Masiga DK (2005) Detection of trypanosomes in small ruminants and pigs in western Kenya important reservoirs in the epidemiology of sleeping sickness? Kinetoplastid Biol Dis 4:5.

10. Welburn SC, Maudlin I (1999) Tsetse-trypanosome interactions: rites of passage. Parasitology Today 15: 399403.

11. Kuzoe FAS, Schofield CJ (2004) Strategic review of traps and targets for tsetse and African trypanosomiasis control. U N I C E F / U N D P / W o r l d B a n k / W H O Special Programme for Research and Training in Tropical Diseases (TDR). TDR/IDE/TRY/05.1.

Corresponding Author: Nigatu Kebede Aklilu Lemma institute of Pathobiology, Addis Ababa University, P. O. Box 1176, Addis Ababa, Ethiopia Tel. +251112763091; Fax +251-11-2755296

Email: nigatukebede@yahoo.com

Conflict of interest: No conflict of interest is declared. 